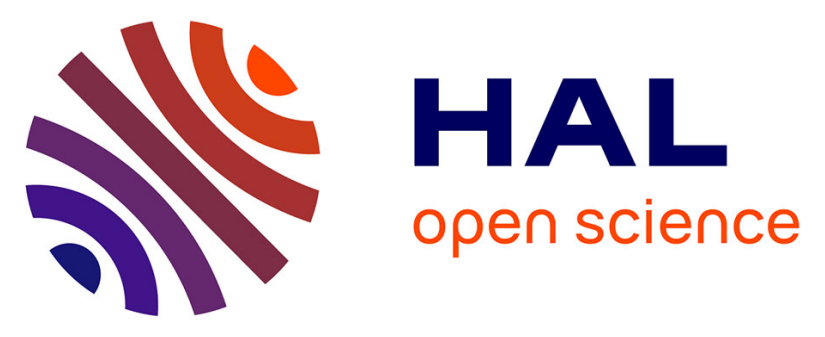

\title{
Role of chemotherapy in 5000 patients with head and neck cancer treated by curative surgery: A subgroup analysis of the meta-analysis of chemotherapy in head and neck cancer
}

\author{
Etienne Dauzier, Benjamin Lacas, Pierre Blanchard, Quynh-Thu Le, \\ Christian Simon, Gregory Wolf, François Janot, Masatoshi Horiuchi, Jeffrey S. \\ Tobias, James Moon, et al.
}

\section{- To cite this version:}

Etienne Dauzier, Benjamin Lacas, Pierre Blanchard, Quynh-Thu Le, Christian Simon, et al.. Role of chemotherapy in 5000 patients with head and neck cancer treated by curative surgery: A subgroup analysis of the meta-analysis of chemotherapy in head and neck cancer. Oral Oncology, 2019, 95, pp.106 - 114. 10.1016/j.oraloncology.2019.06.001 . hal-03485677

\section{HAL Id: hal-03485677 \\ https://hal.science/hal-03485677}

Submitted on 20 Dec 2021

HAL is a multi-disciplinary open access archive for the deposit and dissemination of scientific research documents, whether they are published or not. The documents may come from teaching and research institutions in France or abroad, or from public or private research centers.
L'archive ouverte pluridisciplinaire HAL, est destinée au dépôt et à la diffusion de documents scientifiques de niveau recherche, publiés ou non, émanant des établissements d'enseignement et de recherche français ou étrangers, des laboratoires publics ou privés.

\section{(ㄷ)(1) $\$$}

Distributed under a Creative Commons Attribution - NonCommerciall 4.0 International 
Version of Record: https:/www.sciencedirect.com/science/article/pii/S1368837519301897

TITLE: Role of chemotherapy in $\mathbf{5} \mathbf{0 0 0}$ patients with head and neck cancer treated by curative surgery: a subgroup analysis of the Meta-Analysis of Chemotherapy in Head and Neck Cancer

Authors: Etienne Dauzier ${ }^{1}$, Benjamin Lacas ${ }^{1}$, Pierre Blanchard ${ }^{1,2}$, Quynh-Thu Le ${ }^{3}$, Christian Simon ${ }^{4}$, Gregory Wolf ${ }^{5}$, François Janot ${ }^{6}$, Masatoshi Horiuchi ${ }^{7}$, Jeffrey S. Tobias ${ }^{8}$, James Moon ${ }^{9}$, John Simes ${ }^{10}$, Vinay Deshmane ${ }^{11}$, Jean-Jacques Mazeron ${ }^{12}$, Samir Mehta ${ }^{13}$, Branko Zaktonik ${ }^{14}$, Minoru Tamura ${ }^{15}$, Elizabeth Moyal ${ }^{16}$, Lisa Licitra ${ }^{17}$, Catherine Fortpied ${ }^{18}$, Bruce G. Haffty ${ }^{19}$, Maria Grazia Ghi ${ }^{20}$, Vincent Gregoire $^{21}$, Jonathan Harris ${ }^{22}$, Jean Bourhis ${ }^{23}$, Anne Aupérin ${ }^{1}$, Jean-Pierre Pignon ${ }^{1}$, on behalf of the MACH-NC Collaborative Group*

* Members of the collaborative group are listed in appendix page 1

\section{Affiliations}

1 Ligue Nationale Contre le Cancer, Meta-Analysis Platform, Service de Biostatistique et d'Epidémiologie, Gustave Roussy Cancer Campus, INSERM U1018, CESP, Université Paris-Sud, Université Paris-Saclay, Villejuif, France

${ }^{2}$ Department of Radiation Therapy, Gustave Roussy Cancer Campus, Université Paris-Sud, Université Paris-Saclay, Villejuif, France

${ }^{3}$ Department of Radiation Oncology, Stanford University School of Medicine, Stanford, CA, USA

${ }^{4}$ Department of Otolaryngology and Head and Neck Surgery, Centre Hospitalier Universitaire

Vaudois, Lausanne, Switzerland

${ }^{5}$ Department of Otolaryngology, University of Michigan, Ann Arbor, USA

${ }^{6}$ Département de Cancérologie cervico-faciale, Gustave Roussy Cancer Campus, Université Paris Sud, Villejuif, France

${ }^{7}$ Department of Otolaryngology, Tokai University School of Medicine, Kanagawa, Japan

${ }^{8}$ Department of Radiotherapy, University College London Hospital, London, UK

${ }^{9}$ SWOG Statistical Center, Seattle, WA, USA

${ }^{10}$ NHMRC Clinical Trials Center, Camperdown, Australia

${ }^{11}$ Surgical Oncology \& Breast Diseases, P.D. Hinduja National Hospital \& Medical Research Centre, Mumbai, India

${ }^{12}$ Département de radiothérapie, hôpital Pitié-Salpêtrière, Paris, France

${ }^{13}$ Department of Surgery, Sarla Hospital, Mumbai, India.

${ }^{14}$ Department of Medical Oncology, Institute of Oncology, Ljubljana, Slovenia

${ }^{15}$ Dept. of Dentistry and Oral Surgery, Shinshu University School of Medicine, Japan.

${ }^{16}$ Département de radiothérapie, IUCT Oncopole - CLCC Institut Claudius Regaud, Toulouse, France 
${ }^{17}$ Department of Medical Oncology 3, Fondazione IRCCS-Istituto Nazionale dei Tumori, Milano and University of Milan, Italy

${ }^{18}$ EORTC Headquarters, Brussels, Belgium

${ }^{19}$ Dept. of Therapeutic Radiology, Rutgers Robert Wood Johnson and NJ Medical School, New Jersey, USA

${ }^{20}$ Oncology Unit 2, Veneto Oncology Institute -IRCCS, Padua, Italy

${ }^{21}$ Radiation Oncology Department, Centre Léon Bérard, Lyon, France

${ }^{22}$ NRG Oncology Statistics and Data Management Center, American College of Radiology, Philadelphia, USA

${ }^{23}$ Department of Radiotherapy, Centre Hospitalier Universitaire Vaudois, Lausanne, Switzerland

\section{Corresponding author}

Dr Anne Auperin, Meta-analysis Unit, Biostatistics and Epidemiology Department Institut Gustave Roussy, 114 rue Edouard Vaillant, 94805 Villejuif Cedex, France Phone: 0033142115499

Fax: 0033142115258

e-mail: anne.auperin@gustaveroussy.fr 
1 TITLE: Role of chemotherapy in $\mathbf{5} \mathbf{0 0 0}$ patients with head and neck cancer treated by curative surgery:

2 a subgroup analysis of the Meta-Analysis of Chemotherapy in Head and Neck Cancer

3

4 Word Count: $3497 / 3500$

5 Abstract word count: $250 / 250$

6 Key words: $7 / 10$

7 References: 60/60

8 Figures: 5/7 (Colors for online version only)

9 
11 Objective: To evaluate the effect of chemotherapy added to a surgical locoregional treatment (LRT) for

\section{ABSTRACT} patients with locally advanced head and neck squamous cell carcinoma (HNSCC).

13

14

15

Materials and Methods: We studied the sub-group of trials with surgical LRT included in the metaanalysis on chemotherapy in head and neck cancer (MACH-NC). Data from published and unpublished randomized trials comparing the addition of chemotherapy to LRT in HNSCC patients were sought using electronic database searching for the period 1965-2000, hand searching and by contacting experts in the field. Trials with less than 60 patients, or preoperative radiotherapy or where the type of LRT could not be individually determined were excluded. All individual patient data were checked for internal consistency, compared with published reports, and validated with trialists. Data were pooled using a fixed-effect model. Heterogeneity was assessed using Cochrane test and $\mathrm{I}^{2}$ statistics.

Results: Twenty-four trials were eligible (5000 patients). Chemotherapy improved overall survival $(\mathrm{HR}=0.92$ [95\% $\mathrm{Cl}: 0.85$ to 0.99$] \mathrm{p}=0.02)$. There was a significant interaction between treatment effect and timing of chemotherapy ( $p=0.08$ at pre-specified threshold of 0.1$)$ with a greater effect for concomitant chemotherapy $(\mathrm{HR}=0.79,95 \% \mathrm{Cl}: 0.69$ to 0.92$)$. The benefit of chemotherapy was greater in women $\left(\mathrm{HR}_{\text {women }}=0.63,95 \% \mathrm{Cl}: 0.50\right.$ to 0.80$)$ compared to men $\left(\mathrm{HR}_{\text {men }}=0.96,95 \% \mathrm{Cl}: 0.89\right.$ to $1.04 ; \mathrm{p}$ for interaction $=0.001$ ).

Conclusions: This analysis confirmed the benefit of concomitant chemotherapy added to surgical LRT. The role of induction therapy as yet to be determined as it did not improve OS. Women may benefit more than men from chemotherapy.

Key word: head and neck cancer, squamous cell carcinoma, chemotherapy, surgery, meta-analysis, individual patient data, randomized trial 
33 Addition of chemotherapy to surgery improved overall survival in head \& neck cancer.

34 Improvement of overall survival was greater with concomitant chemotherapy.

35 Induction chemotherapy did not significantly improved overall survival

36 Women benefited from chemotherapy more than men.

37 Effect of sex on survival should be investigated more in head and neck cancer.

38

Conflict Of Interest statement

$40 \quad$ None declared

41

42 Abbreviations

43 HNSCC : Head and neck Squamous cell carcinoma

44 HR: Hazard Ratio

$45 \quad 95 \% \mathrm{Cl}: 95 \%$ Confidence interval

46 IPD: Individual patient data

47 LRT: Locoregional Treatment

48 OS: Overall survival

49 MACH-NC: Meta-analysis of Chemotherapy in Head and Neck Cancer 


\section{INTRODUCTION}

Every year, more than 600000 patients are diagnosed with head and neck cancer worldwide ${ }^{1}$. Most of these cancers are squamous cell carcinomas (HNSCC); half of them diagnosed at locally advanced stage ${ }^{2}$. In the individual patient data (IPD) meta-analysis of randomized clinical trials MACH-NC (Meta-analysis of Chemotherapy in Head and Neck Cancer), we showed that the addition of chemotherapy to locoregional treatment (LRT) improved overall survival (OS) in locally advanced non-metastatic HNSCC ${ }^{3}$. This metaanalysis of 87 trials completed between 1965 and 2000 included 16485 patients. Hazard ratio (HR) for death was 0.88 (95\% confidence interval $(95 \% \mathrm{Cl}): 0.85$ to $0.92 ; \mathrm{p}<.001)$ with an absolute benefit on survival of $4.5 \%$ at 5 years. Benefit was significantly more pronounced for chemotherapy concomitant to radiotherapy with a $6.5 \%$ benefit at 5 years ( $\mathrm{HR}=0.81,95 \% \mathrm{Cl} 0.78$ to 0.86$)$. In this meta-analysis, patients treated by surgery, radiotherapy, or both were analyzed together. However, patients' characteristics usually differ between trials that included patients treated by surgery as primary LRT and trials that included patients treated by radiotherapy only. For example, in a study on oral cavity cancer, patients treated by surgery were younger and had lower stage cancer ${ }^{4}$. In a preliminary analysis of the MACH-NC database, we compared patients treated by surgery (+/- radiotherapy) to patients treated by radiotherapy only. Among the patients included in this preliminary analysis (eTable 1), 5352 (32.9\%) had surgery as LRT. These patients had lower stage tumors ( $48 \%$ stage IV versus $65 \%$ for radiotherapy patients; $\mathrm{p}<.001$ ) and had oral cavity tumors more frequently (33\% versus $21 \%$ for radiotherapy patients; $p<.001)$. Age, sex, and performance status were also significantly different. Forty per cent of patients treated by surgery received induction chemotherapy whereas only $21 \%$ of patients treated by radiotherapy did. Because patients treated by surgery are different, the effect of chemotherapy and its interaction with patient characteristics on their survival might vary. Moreover the addition of surgery in LRT changes the adverse events patients may encounter and modifies the timing of radiotherapy. Finally, although the MACH-NC meta-analysis showed no effect of induction therapy on survival, the use of 
induction chemotherapy is still debated, especially when surgery is considered for $L R T^{5-7}$. Thus, it was decided to perform a specific analysis of patients treated by surgery in the MACH-NC database.

The primary objective was to evaluate the benefit on overall survival of chemotherapy in addition to a surgical LRT for patients diagnosed with locally advanced HNSCC. There were two secondary objectives: first, to investigate interaction between the effect of chemotherapy and patient or trial characteristics; and second, to study event-free survival and the different types of failure.

\section{METHODS}

The protocol for this meta-analysis was redacted prior to the analysis and is available at: https://www.gustaveroussy.fr/sites/default/files/protocol_mach_nc_surg.pdf

\section{$\underline{\text { Trial selection }}$}

This meta-analysis studied the subgroup of patients treated by surgery in the MACH-NC database.

Selection of included trials was described in previous publications ${ }^{3}$. All trials had to include previously untreated patients with locally advanced non-metastatic HNSCC. Accrual had to be completed between 1965 and 2000. Trials had to use a randomization method that precluded prior knowledge of treatment assignment. To be eligible in this analysis, trials had to compare curative surgical LRT (+/- radiotherapy) versus the addition of chemotherapy to the same LRT. The timing of chemotherapy could be before surgery (induction), during post-operative radiotherapy (concomitant) or after the end of the LRT (adjuvant). Trials with less than 60 patients or with systematic preoperative radiotherapy were excluded. Trials in which the patients could be treated by surgery (+/- radiotherapy) or radiotherapy alone, and in which the type of LRT could not be individually determined were excluded, except if more than $50 \%$ of patients had surgery. Both published and unpublished trials were included.

\section{Data collection and consistency checking}


The data collected for each patient were: age, sex, tumor stage, tumor site, performance status, treatment allocated, survival and failure status, date of randomization, date of first failure, date of death or date of last follow up. Information retrieved for each trial was: the timing of chemotherapy, the type of chemotherapy (number and type of drugs), and the neck dissection strategy. For induction trials, information on surgical margins strategy, planned number of chemotherapy cycles and possibility of early LRT for non-responding patients was also collected. All IPD were checked with a standard procedure $3,8,9$, which follows the recommendations of the Cochrane working group on meta-analysis using IPD. Results were compared with protocol (when available) and published reports, and validated with the corresponding trialist.

\section{$\underline{\text { Outcomes }}$}

Primary endpoint was overall survival (OS), defined as the time from randomization to death from any cause. Secondary endpoints were early death and event-free survival. Death was considered early when it occurred within 6 months after randomization. Event-free survival was defined as the time from randomization to the first event ${ }^{10}$ (locoregional failure, distant failure, or death from any cause). Living patients that presented no event were censored at their date of last follow up. Events considered as locoregional failures were local failure, regional failure, or concomitant local and regional failure without concomitant distant failure. Events considered as distant failure were distant failure, either alone or combined with local or regional failure. Events considered as death without failure were death without previous locoregional or distant event.

\section{$\underline{\text { Statistical Analysis }}$}

All randomized patients were included in an intent-to-treat analysis. Median follow up was calculated with the reverse Kaplan-Meier method ${ }^{11}$. Analyses were stratified by trial. We calculated trial and overall pooled hazard ratios (HR) using the log-rank expected number of events and variance, using a fixed 
effect model. Stratified survival curves were computed for control and experimental groups using Peto's

120 method and were used to calculate absolute benefit at 5 years ${ }^{12,13}$. Heterogeneity of chemotherapy

121 effect among trials was assessed using $\chi^{2}$ heterogeneity test and $\mathrm{I}^{2}$ statistic ${ }^{14}$. Because heterogeneity

122 test is not powerful, we chose a 0.10 significance threshold ${ }^{15}$. In case of significant heterogeneity, we

123 performed sensitivity analysis to identify the source of heterogeneity. If heterogeneity was still

124 significant and unexplained, we used a random-effect model ${ }^{15,16}$.

125 Three sensitivity analyses were planned by exclusion of some trials: with less than 100 patients, with a

126 median follow up $<5$ years, and whose accrual period began before 1980 . We also conducted a post hoc

127 analysis where outlier trials (trials that had a $95 \% \mathrm{Cl}$ that did not overlap with the $95 \% \mathrm{Cl}$ of the global HR)

128 were excluded.

129 In subset analyses, we used $\chi^{2}$ heterogeneity tests among different groups of trials to study interaction

130 between trial characteristics and treatment effect. The residual heterogeneity within trial subgroups was

131 the difference between the overall $\chi^{2}$ heterogeneity statistics and the $\chi^{2}$ heterogeneity statistic

132 between groups ${ }^{17}$. Trial subsets were predefined according to: timing of chemotherapy, type of

133 chemotherapy drugs, and neck dissection strategy (not performed because of high rate of missing data);

134 for induction trials, surgical margins strategy, type of induction protocol (number of cycles, possibility of

135 early LRT). We performed two post hoc analyses: the first studied the type of chemotherapy in induction

136 trials and the second, the administration of radiotherapy in adjuvant trials. We investigated interaction

137 between treatment effect and patients characteristics (age, stage, sex, performance status, and primary

138 site of tumor) in a Cox model stratified by trial that included treatment arm, covariate and interaction.

139 Trials in these analyses had to include patients in all categories of the variable under study. In case of

140 significant interaction, the results were confirmed in a multivariate model including the other individual

141 characteristics. Since only the first event was collected in the meta-analysis, locoregional failure, distant

142 failure, and death without failure were analyzed using Fine and Gray models (unplanned competing risk 

analysis), version 3.2.5. interpretation, or in the writing of the report.

\section{RESULTS}

\section{Population}

Among the 87 trials included in MACH-NC database we identified 39 that proposed a surgical LRT. Fifteen

151 of those met predefined exclusion criterions (eFigure 1). The meta-analysis included 24 trials ${ }^{20-43}$ (5 000

152 patients) evaluating surgical LRT versus the same LRT + chemotherapy (eTable2). One trial (UKHAN-1 ${ }^{43}$ )

153 had two strata comparisons based on the type of chemotherapy and was considered above as two

154 distinct trials. There were 7 adjuvant chemotherapy trials (1 743 patients), 11 induction chemotherapy

155 trials (1 925 patients) and 6 concomitant trials (1 332 patients). Two trials were unpublished (BNH003 ${ }^{29}$,

156 EORTC $24844^{32}$ ) and two were published as abstracts only (AHNTG ${ }^{27}$, GETTECadj ${ }^{20}$ ). Postoperative

157 radiotherapy was planned in most of trials. Five adjuvant trials ${ }^{21,23-26}$ had only surgery as LRT (933/1 743

158 patients of adjuvant trials). Overall median follow up was 4.9 years (range: 1.3 to 13.7 years). Description

159 of the overall population is available in eTable 3. Number of events in each arm is given for all endpoints

160 in eTable 4.

161 Overall survival and event-free survival

162 There were 2696 deaths. Chemotherapy improved OS (HR=0.92 [95\% Cl: 0.85 to 0.99] p=0.02, figure 1),

163 with an absolute benefit of $4.4 \%(95 \% \mathrm{Cl}: 1.3$ to $7.5 \%)$ at 5 years (figure 2$)$. There was a significant

164 interaction between treatment effect and timing of chemotherapy $(p=0.08$ at pre-specified threshold of 
165

166

167

168

169

170

171

172

173

174

175

176

177

178

179

180

181

182

0.10 ) with a greater effect for concomitant chemotherapy ( $\mathrm{HR}=0.79,95 \% \mathrm{Cl}: 0.69$ to 0.92$)$ than for induction ( $\mathrm{HR}=0.96,95 \% \mathrm{Cl}: 0.85$ to 1.08 ) or adjuvant chemotherapy ( $\mathrm{HR}=0.98,95 \% \mathrm{Cl}: 0.85$ to 1.12 ). Heterogeneity was significant but moderate $\left(I^{2}=35 \% ; p=0.04\right)$. Results of sensitivity analyses showed similar results for treatment effect and heterogeneity (eTable 5), except for the one based on trials with follow-up longer than 5 years ( $p$ for treatment effect $=0.40$ ) and the post-hoc analysis excluding two outlier trials previously identified ${ }^{44}$ (GETTECadj ${ }^{20}$ and Toulouse $^{38} ; \mathrm{p}$ for heterogeneity $=0.39$ ).

For event-free survival, based on 23 trials and 4501 patients (2 659 events), similar results were observed (eFigure 2), with an overall HR of 0.90 ( $95 \% \mathrm{Cl}: 0.84$ to $0.98 ; p=0.01$ ) and an absolute benefit of $3.3 \%$ (95\% Cl: 0.1 to $6.5 \%)$ at 5 years (eFigure 3). There was a significant interaction between treatment effect and timing of chemotherapy $(p=0.05)$ with a greater effect for concomitant chemotherapy $(\mathrm{HR}=0.78,95 \% \mathrm{Cl}: 0.68$ to 0.90$)$ than for induction ( $\mathrm{HR}=0.98,95 \% \mathrm{Cl}: 0.88$ to 1.10$)$ and adjuvant chemotherapy (HR=0.91, 95\% Cl: 0.78 to 1.07$)$. Heterogeneity was also significant $\left(I^{2}=46 \%, p\right.$ for heterogeneity $=0.03$ ).

Within 6 months after randomization, 323 deaths occurred. Overall HR for the effect of chemotherapy on early death was 1.21 ( $95 \% \mathrm{Cl}: 0.97$ to $1.51, \mathrm{p}=0.08)$ without significant difference between concomitant chemotherapy ( $\mathrm{HR}=0.98,95 \% \mathrm{Cl}: 0.65$ to 1.47$)$, induction therapy $(\mathrm{HR}=1.36,95 \% \mathrm{Cl}: 0.96$ to 1.94 ), or adjuvant chemotherapy ( $\mathrm{HR}=1.28,95 \% \mathrm{Cl}: 0.87$ to 1.90 ; $\mathrm{p}$ for interaction $=0.45$, eFigure 4$)$.

\section{Subset analyses}

The effect of chemotherapy on OS was significantly different according to the type of chemotherapy ( $p$ for interaction $=0.02)$ : the $\mathrm{HR}$ was $0.74(95 \% \mathrm{Cl}: 0.62$ to 0.88$)$ for platinum alone, $0.88(95 \% \mathrm{Cl}: 0.76$ to 1.02) for poly-chemotherapies based on platinum and 5-Fluorouracil (PF), 0.90 ( $95 \% \mathrm{Cl}: 0.74$ to 1.11) for other mono-chemotherapies and $1.04(95 \% \mathrm{Cl}: 0.92$ to 1.17$)$ for other poly-chemotherapies. The benefit of PF based chemotherapy was not significant in induction trials alone (eTable 6). No significant interaction was observed between chemotherapy effect and the type of induction protocol, or the 
190 or modalities of LRT (surgery vs.surgery + RT) for adjuvant trials.

\section{Sub-group analyses}

192 A significant interaction between chemotherapy effect and patients' sex was found (Figure 3). Benefit of 193 chemotherapy on OS was greater for women $\left(\mathrm{HR}_{\text {women }}=0.63,95 \% \mathrm{Cl}: 0.50\right.$ to 0.80$)$ than for men

$194\left(\mathrm{HR}_{\mathrm{men}}=0.96,95 \% \mathrm{Cl}: 0.89\right.$ to $1.04 ; \mathrm{p}$ for interaction <.001). Heterogeneity of interaction between

195 treatment and sex was not significant ( $p$ for heterogeneity $=0.81$, eFigure 5 and eTable7). Event-free 196 survival showed similar results $\left(\mathrm{HR}_{\text {women }}=0.63(95 \% \mathrm{Cl}: 0.50\right.$ to 0.80$)$ versus $\mathrm{HR}_{\text {men }}=0.95(95 \% \mathrm{Cl}: 0.87$ to 197 1.03); $\mathrm{p}$ for interaction $=0.001)$.

198 The 718 (14\%) women included in this study differed from the 4262 (85\%) men in age (younger), stage 199 (lower), performance status (better) and tumor site (more oral cavity, eTable 8). As all these covariates 200 significantly influenced survival (eTable 9), a multivariate interaction model adjusted on age, site and 201 stage was implemented and confirmed a significant interaction $\left(\mathrm{HR}_{\text {women }}=0.62(95 \% \mathrm{Cl}: 0.49\right.$ to 0.79$)$, 202 versus $\mathrm{HR}_{\text {men }}=0.96$ ( $95 \% \mathrm{Cl}: 0.88$ to 1.04$) ; \mathrm{p}$ for interaction <.001). Performance status was not included 203 because of missing data, but a sensitivity analysis including this covariate leads to similar results $204\left(\mathrm{HR}_{\text {women }}=0.59\right.$ (95\% Cl: 0.45 to 0.77$)$, versus $\mathrm{HR}_{\text {men }}=0.99$ (95\% $\mathrm{Cl}: 0.89$ to 1.09$) ; p$ for interaction <.001).

205 Absolute benefit at 5 years was $13.3 \%$ (95\% Cl: 9.1 to $17.5 \%$ ) for women and 3.0\% ( $95 \% \mathrm{Cl}:-0.6$ to $6.4 \%$ ) 206 for men (figure 4). A leave-one-out sensitivity analysis (post hoc analysis, efigure 6), showed that the 207 RTOG $9501^{42}$ trial influenced interaction more than other trials. After exclusion of the RTOG trial ${ }^{42}$, 208 interaction was still significant $\left(\mathrm{HR}_{\text {women }}=0.69(95 \% \mathrm{Cl}: 0.54\right.$ to 0.89$)$ versus $\mathrm{HR}_{\text {men }}=0.95(95 \% \mathrm{Cl}: 0.88$ to 209 1.04); $\mathrm{p}$ for interaction $=0.02$ ). 
211 Because two trials had no information on locations of failures (Int0034 22 and JHCFUS ${ }^{23}$ ), only 4291

212 patients were included in the failure analysis (eTable 4). Chemotherapy decreased significantly the

213 incidence of locoregional failure $(\mathrm{HR}=0.80,95 \% \mathrm{Cl}: 0.70$ to $0.90 ; \mathrm{p}<.001)$ (Figure 5) but the decrease was

214 not significant for distant failure ( $\mathrm{HR}=0.87,95 \% \mathrm{Cl}: 0.75$ to $1.00 ; \mathrm{p}=0.06)$. Patients treated with

215 chemotherapy died without failure more than non-treated patients ( $\mathrm{HR}=1.20,95 \% \mathrm{Cl}: 1.06$ to 1.37 ;

$216 p=0.01)$. Patterns of failure were different between the different chemotherapy timing, particularly on

217 locoregional failure: significant benefit in concomitant and adjuvant trials but not on induction trials

218 (Figure5, eTable 10). Effect of chemotherapy on distant failure was non-significant for the three

219 chemotherapy timings.

220 Men and women had significantly different hazards for death without failure $\left(\mathrm{HR}_{\text {women }}=0.78(95 \% \mathrm{Cl}: 0.53\right.$

221 to 1.15$)$ versus $\mathrm{HR}_{\text {men }}=1.26(95 \% \mathrm{Cl}: 1.10$ to 1.45$)$; $\mathrm{p}$ for interaction $\left.=0.02\right)$. Differences were not

222 significant for locoregional failure $\left(\mathrm{HR}_{\text {women }}=0.66(95 \% \mathrm{Cl}=0.46\right.$ to 0.94$)$ versus $\mathrm{HR}_{\text {men }}=0.82(95 \% \mathrm{Cl}: 0.72$ to

$2230.94) ; \mathrm{p}$ for interaction $=0.26)$ or for distant failure $\left(\mathrm{HR}_{\text {women }}=0.66(95 \% \mathrm{Cl}: 0.46\right.$ to 1.11$)$ versus $H \mathrm{R}_{\text {men }}=0.82$

224 (95\% Cl: 0.77 to $1.04 ; \mathrm{p}$ for interaction $=0.35)$.

DISCUSSION

This meta-analysis on individual patient data is the first to investigate the effect of chemotherapy added

227 to surgical locoregional treatment (LRT) in HNSCC. The results confirmed those obtained in the MACH-NC overall analysis ${ }^{3}$. The addition of chemotherapy to LRT improved patients' survival. Interaction with

229 chemotherapy timing was significant and a benefit was particularly observed for concomitant

230 chemotherapy.

231 Heterogeneity in our analysis was moderate $\left(I^{2}=35 \%\right)$. A major source of heterogeneity came from two

232 French trials: GETTECadj ${ }^{20}$ and Toulouse ${ }^{38}$. Both trials selected patients with very high risk of failure as

233 they only included patients with invaded surgical margins and extra capsular invasion of cervical lymph 
nodes. Both trials were already pointed out as heterogeneous trials in a previous work on heterogeneity

235 in the MACH-NC database ${ }^{44}$. As we had limited information on toxicity, early deaths were analyzed as a

236 proxy of drug induced mortality, including potential impact on postoperative mortality but no significant

237 difference was found.

238 The effect of chemotherapy was consistent in all sensitivity analyses (except for trials with long follow-

239 up), as in analyses on event-free survival. The unplanned competing risk analysis suggested that

240 chemotherapy was most effective on locoregional failure. It showed that, for all chemotherapy timings,

241 treatment effect on distant failure was not significant. Mono-chemotherapy using platinum increased

242 patients' survival more than other chemotherapies. Interaction between chemotherapy and

243 radiotherapy by comparing the subset of trials with surgery and the subset of trials with surgery plus

244 radiotherapy could be investigated only in adjuvant subset as the induction subset did not include trials

245 with surgery alone: the interaction was not significant. Moreover, sensitivity analysis based only on trials

246 with surgery plus radiotherapy (excluding trials with surgery only or mixed (surgery or surgery plus

247 radiotherapy) locoregional treatment) showed similar results than the main analysis.

A majority of trials in this meta-analysis proposed induction chemotherapy. Despite a moderate effect on survival ${ }^{3}$, induction therapy is sometimes advocated to reduce the risk of distant metastasis and to reduce the tumor volume before surgery ${ }^{5}$. In our population of patients included in surgical trials, induction therapy showed no significant benefit on overall survival or event-free survival. There was no benefit on locoregional or distant failure. Effect was not significantly different for trials that proposed only one cycle of chemotherapy or that allowed non-responding patients to have early surgery.

254 However, no trials proposed taxane in addition to $\mathrm{PF}$, a strategy that proved significant benefit ${ }^{45}$ over

255 induction PF. Except for a recent trial ${ }^{46}$, trials comparing taxane + PF to PF alone did not include surgery as $\mathrm{LRT}^{47,48}$ and could not be included in our meta-analysis. Finally, we could not study the benefit of 
induction chemotherapy on organ preservation as trials included in this meta-analysis were not designed

258 to study organ preservation strategies.

259 An unexpected interaction between treatment effect and patients' characteristics was found for sex. This 260 differed from the overall MACH-NC analysis. In the MACH-NC analysis interaction was found only with 261 age (chemotherapy effect was poorer for patients older than 70 years old). This may result from 262 differences in patients' characteristics: patients treated by surgery are younger; only 387 (7.7\%) of our 263 patients were older than 70 years and thus were analyzed in the $\geq 60$ years old group. As the surgical 264 subgroup only represent $28.6 \%$ (5 000/17 483) of the MACH-NC population, $23.4 \%$ (2 696/11 542) of 265 observed deaths, and $14.3 \%$ of the patients included in concomitant trials (1 327/9 305), this interaction 266 might have been diluted in the overall analysis (eTable 1). This interaction was consistent for OS in 267 univariate and multivariate analyses. Results were similar for event-free survival. The study of the 268 heterogeneity of the interaction (eFigure5) and of the hazard ratios of treatment effect by sex (eTable7) showed the consistency of the interaction throughout all trials; the leave-one-out analysis (eFigure6) showed the robustness of the results. The effect of chemotherapy on the different type of failure in men

271 and women showed no significant difference on locoregional and distant failure. Men treated with

272 chemotherapy had a significantly higher incidence of death without failure. Interpretation of this

273 outcome was made difficult because of missing information on the exact cause of death. A lower rate of 274 comorbidities and of mortality not related to cancer in women than men may explain the observed 275 results. Despite the improvement over time of tumor control in HNSCC, survival increased moderately. 276 Authors pointed out that patients face many competing risks of death (toxicity, comorbidities, or second 277 malignancies $)^{49}$. In a recent communication, Park and al found that women with HNSCC died less from 278 other causes than from their tumors compared to $\mathrm{men}^{50}$. Sex effect on toxicity and efficacy of systemic 279 treatment are debated, but often considered as understudied ${ }^{51}$. The prognostic value of sex has long 280 been discussed in HNSCC $^{52-55}$; most of the time the better survival of women was linked to lower stage 
tumors or better performance status. In a study evaluating multiple cancers and sex-specific survival,

282 Cook and al found better adjusted survival for women in flour of mouth and laryngeal cancer ${ }^{56}$. Similar

283 results were observed in the controls arms (i.e. without chemotherapy) of the whole MACH-NC

284 database ${ }^{57}$. The study of interaction between chemotherapy effect and sex is often difficult because of

285 the few women included in clinical trials. Only large trials or meta-analyses have sufficient power to

286 investigate such interaction and explore the predictive value of sex. As the exploration of sex differences

287 in medicine are actually promoted ${ }^{58}$, future HNSCC trials should plan to stratify accrual on sex and to

288 study differences in efficacy and toxicity according to patients' sex.

289 Lack of power and risk of false positive are the main limitations of this study. Our population is a

290 subgroup of the MACH-NC patients treated with chemotherapy, but still allows an exhaustive synthesis

291 of most surgical trials available. Negative results such as the non-significant interaction between age and

292 chemotherapy effect, between early death and chemotherapy timing or non-significant effect of

293 chemotherapy on distant failure could be related to the lack of power. On the other hand, the

294 unexpected interaction with sex could be a false positive, but we found consistent results in favor of such

295 effect in exploratory analyses. Some trials included are old, patients were accrued between 1974 and

2962000 , and our results may not represent contemporary treatment strategies. Among the trials eligible for

297 the next update of MACH-NC, we have identified 2 concomitant trials ${ }^{59,60}$ and one induction trial ${ }^{46}$ (476

298 patients) with surgical LRT, and sensitivity analysis adding these 3 more recent trials showed similar

299 results (data not shown). Another limitation was missing data. Some data were partially missing, such as

300 performance status, other were totally missing, such as HPV status, tobacco and alcohol consumption,

301 pathological characteristics, compliance to chemotherapy, or patients' comorbidity. This may be a

302 confounding factor in our analysis. However, all patients were included in randomized trials with

303 homogeneous inclusion and exclusion criteria and had limited comorbidities as surgery was possible,

304 minimizing differences between compared groups. 
305 To conclude, this analysis confirmed the benefit of chemotherapy in addition to surgical LRT, however

306 benefit in OS was modest and may be limited to the use of platin, concomitant timing and/or to females.

307 The place of induction therapy has yet to be determined as it did not improved survival for patients

308 treated with induction chemotherapy followed by surgery. Our results suggested that women benefited

309 more from chemotherapy than men. Interaction between sex and chemotherapy should be further

310 investigated to confirm our results. As the benefit of chemotherapy in HNSCC is now widely

311 acknowledged, fewer trials compare chemotherapy in addition to LRT versus LRT only. Future analyses of

312 chemotherapy effect in HNSCC will require IPD network meta-analysis to provide high-level evaluation of

313 available treatments.

\section{Acknowledgment}

315 We thank the trialists and the collaborative groups who agreed to share their data. The contents of this

316 publication and methods used are solely the responsibility of the authors and do not necessarily

317 represent the official views of the ECOG-ACRIN Cancer Research Group, and NRG Oncology. This research

318 was funded by grants from Institut National du Cancer (Programme Hospitalier de Recherche Clinique)

319 and Ligue Nationale Contre le Cancer. ED was recipient of a scholarship of the Fondation ARC pour la

320 recherche contre le cancer for his master of science. ED and JPP had full access to all the data in the study

321 and take responsibility for the integrity of the data and the accuracy of data analysis. 
1. Ferlay J, Soerjomataram I, Dikshit R, et al. Cancer incidence and mortality worldwide: Sources, methods and major patterns in GLOBOCAN 2012: Globocan 2012. Int J Cancer. 2015;136:E359-E386. doi:10.1002/ijc. 29210

2. Baxi SS, Pinheiro LC, Patil SM, Pfister DG, Oeffinger KC, Elkin EB. Causes of death in long-term survivors of head and neck cancer: Competing Mortality in HNSCC Survivors. Cancer. 2014;120(10):1507-1513. doi:10.1002/cncr.28588

3. Pignon J-P, Le Maître A, Maillard E, Bourhis J. Meta-analysis of chemotherapy in head and neck cancer (MACH-NC): An update on 93 randomised trials and 17,346 patients. Radiother Oncol. 2009;92:4-14. doi:10.1016/j.radonc.2009.04.014

4. Fujiwara RJT, Burtness B, Husain ZA, et al. Treatment guidelines and patterns of care in oral cavity squamous cell carcinoma: Primary surgical resection vs. nonsurgical treatment. Oral Oncol. 2017;71:129137. doi:10.1016/j.oraloncology.2017.06.013

5. Busch C-J, Tribius S, Schafhausen P, Knecht R. The current role of systemic chemotherapy in the primary treatment of head and neck cancer. Cancer Treat Rev. 2015;41(3):217-221. doi:10.1016/j.ctrv.2015.02.002

6. Ma J, Liu Y, Huang X-L, et al. Induction chemotherapy decreases the rate of distant metastasis in patients with head and neck squamous cell carcinoma but does not improve survival or locoregional control: A meta-analysis. Oral Oncol. 2012;48(11):1076-1084. doi:10.1016/j.oraloncology.2012.06.014 7. Mak MP, Glisson BS. Is there still a role for induction chemotherapy in locally advanced head and neck cancer?: Curr Opin Oncol. 2014;26(3):247-251. doi:10.1097/CCO.0000000000000073 patient data. Cochrane Working Group. Stat Med. 1995;14(19):2057-2079. 
9. Lacas B, Bourhis J, Overgaard J, et al. Role of radiotherapy fractionation in head and neck cancers (MARCH): an updated meta-analysis. Lancet Oncol. 2017;18(9):1221-1237. doi:10.1016/S14702045(17)30458-8

10. Michiels S, Le Maître A, Buyse M, et al. Surrogate endpoints for overall survival in locally advanced head and neck cancer: meta-analyses of individual patient data. Lancet Oncol. 2009;10:341-350. doi:10.1016/S1470-2045(09)70023-3

11. Schemper M, Smith TL. A note on quantifying follow-up in studies of failure time. Control Clin Trials. 1996;17:343-346.

12. Yusuf S, Peto R, Lewis J, Collins R, Sleight P. Beta blockade during and after myocardial infarction: an overview of the randomized trials. Prog Cardiovasc Dis. 1985;27:335-371.

13. Lueza B, Rotolo F, Bonastre J, Pignon J-P, Michiels S. Bias and precision of methods for estimating the difference in restricted mean survival time from an individual patient data meta-analysis. BMC Med Res Methodol. 2016;16. doi:10.1186/s12874-016-0137-z

14. Higgins JPT, Thompson SG. Quantifying heterogeneity in a meta-analysis. Stat Med. 2002;21:15391558. doi:10.1002/sim.1186

15. Pignon J-P, Hill C. Meta-analyses of randomised clinical trials in oncology. Lancet Oncol. 2001;2:475482. doi:10.1016/S1470-2045(01)00453-3

16. DerSimonian R, Laird N. Meta-analysis in clinical trials. Control Clin Trials. 1986;7:177-188.

17. Chemotherapy in non-small cell lung cancer: a meta-analysis using updated data on individual patients from 52 randomised clinical trials. Non-small Cell Lung Cancer Collaborative Group. BMJ. 1995;311(7010):899-909.

18. Fine JP, Gray RJ. A Proportional Hazards Model for the Subdistribution of a Competing Risk. J Am Stat Assoc. 1999;94:496. doi:10.2307/2670170

19. Latouche A, Allignol A, Beyersmann J, Labopin M, Fine JP. A competing risks analysis should report results on all cause-specific hazards and cumulative incidence functions. J Clin Epidemiol. 2013;66(6):648653. doi:10.1016/j.jclinepi.2012.09.017

20. Domenge $C$, Marandas $P$, Vignoud J. Post-surgical adjuvant chemotherapy in extracapsular spread invaded lymph node $(\mathrm{N}+\mathrm{R}+)$ of epidermoid carcinoma of the head and neck: a randomized multicentric trial. Second international conference on head and neck cancer. Boston. Am Soc Head Neck Surg 1988; 74 abstr).

21. Tsukuda M, Ogasawara $\mathrm{H}$, Kaneko $\mathrm{S}$, et al. [A prospective randomized trial of adjuvant chemotherapy with UFT for head and neck carcinoma. Head and Neck UFT Study Group]. Gan To Kagaku Ryoho. 1994;21(8):1169-1177. 
22. Laramore GE, Scott CB, al-Sarraf M, et al. Adjuvant chemotherapy for resectable squamous cell carcinomas of the head and neck: report on Intergroup Study 0034. Int J Radiat Oncol Biol Phys. 1992;23(4):705-713.

23. Yoshino K, Sato T, Nakai Y, et al. [A comparative clinical study on the treatment of head and neck tumors by adjuvant chemotherapy with HCFU--Second Study by Kinki Head and Neck Tumor Study Group]. Gan To Kagaku Ryoho. 1994;21(6):777-783.

24. Kotani A, Sunada O, Tamura M, et al. [Multiple cooperative study of UFT-adjuvant chemotherapy for malignant tumor in the jaw and oral cavities. The Oral Surgery Malignant Tumor Research Association in Kanto Kohshinetsu District]. Gan To Kagaku Ryoho. 1994;21(7):987-992.

25. Rao RS, Parikh DM, Parikh HK, Bhansali MB, Deshmane VH, Fakih AR. Perioperative chemotherapy in patients with oral cancer. Am J Surg. 1994;168(3):262-267.

26. Szpirglas H, Chastang C, Bertrand JC. Adjvant treatment of tongue and floor of the mouth cancers. Recent Results Cancer Res Fortschritte Krebsforsch Progres Dans Rech Sur Cancer. 1978;68:309-317.

27. Dalley $D$, Beller $E$, Aroney, $R$, et al. The value of chemotherapy (CT) prior to definitive local therapy (DTL) in patients with locally advanced squamous cell carcinoma (SCC) of the head and neck (HN). Proc ASCO 1995; 14: 297.

28. Domenge C, Hill C, Lefebvre JL, et al. Randomized trial of neoadjuvant chemotherapy in oropharyngeal carcinoma. French Groupe d'Etude des Tumeurs de la Tête et du Cou (GETTEC). Br J Cancer. 2000;83(12):1594-1598. doi:10.1054/bjoc.2000.1512

29. Metha S. BNH 03-Anterior (neoajuvant) chemotherapy in advanced resectable cancers of the oral cavity and oropharynx. Personal communication on behalf of the B. Nanavati Hospital group. Unpublished.

30. Volling P, Schroder M, Muller R, Ebeling O, Quirin R, Stennert E. Induction chemotherapy in primary resectable head and neck tumors - a prospective randomized trial. Int J Oncol. 1994;4(4):909-914.

31. Mazeron JJ, Martin M, Brun B, et al. Induction chemotherapy in head and neck cancer: results of a phase III trial. Head Neck. 1992;14(2):85-91.

32. Lefebvre JL, Sahmoud T, Kirkpatrick A. EORTC 24844 trial. Randomized trial of induction chemotherapy followed by surgery and postoperative radiotherapy versus surgery and postoperative radiotherapy alone in advanced squamous cell carcinoma of the lateral oropharynx and lateral posterior oral cavity. Personal communication on behalf of the EORTC Head and Neck Cancer Cooperative Group.

33. Paccagnella A, Orlando A, Marchiori C, et al. Phase III trial of initial chemotherapy in stage III or IV head and neck cancers: a study by the Gruppo di Studio sui Tumori della Testa e del Collo. J Nat/ Cancer Inst. 1994;86(4):265-272.

34. Schuller DE, Metch B, Stein DW, Mattox D, McCracken JD. Preoperative chemotherapy in advanced 
resectable head and neck cancer: final report of the Southwest Oncology Group. The Laryngoscope. 1988;98(11):1205-1211. doi:10.1288/00005537-198811000-00011

35. Jortay A, Demard F, Dalesio O, et al. A randomized EORTC study on the effect of preoperative polychemotherapy in pyriform sinus carcinoma treated by pharyngolaryngectomy and irradiation. Results from 5 to 10 years. Acta Chir Belg. 1990;90(3):115-122.

36. Richard JM, Kramar A, Molinari R, et al. Randomised EORTC head and neck cooperative group trial of preoperative intra-arterial chemotherapy in oral cavity and oropharynx carcinoma. Eur J Cancer Oxf Engl 1990. 1991;27(7):821-827.

37. Adjuvant chemotherapy for advanced head and neck squamous carcinoma. Final report of the Head and Neck Contracts Program. Cancer. 1987;60(3):301-311.

38. Bachaud JM, Cohen-Jonathan E, Alzieu C, David JM, Serrano E, Daly-Schveitzer N. Combined postoperative radiotherapy and weekly cisplatin infusion for locally advanced head and neck carcinoma: final report of a randomized trial. Int J Radiat Oncol Biol Phys. 1996;36(5):999-1004.

39. Weissberg JB, Son YH, Papac RJ, et al. Randomized clinical trial of mitomycin $\mathrm{C}$ as an adjunct to radiotherapy in head and neck cancer. Int J Radiat Oncol Biol Phys. 1989;17(1):3-9.

40. Bernier J, Domenge C, Ozsahin M, et al. Postoperative irradiation with or without concomitant chemotherapy for locally advanced head and neck cancer. N Engl J Med. 2004;350(19):1945-1952. doi:10.1056/NEJMoa032641

41. Smid L, Budihna M, Zakotnik B, et al. Postoperative concomitant irradiation and chemotherapy with mitomycin $\mathrm{C}$ and bleomycin for advanced head-and-neck carcinoma. Int J Radiat Oncol Biol Phys. 2003;56(4):1055-1062.

42. Cooper JS, Pajak TF, Forastiere AA, et al. Postoperative concurrent radiotherapy and chemotherapy for high-risk squamous-cell carcinoma of the head and neck. N Engl J Med. 2004;350(19):1937-1944. doi:10.1056/NEJMoa032646

43. Tobias JS, Monson K, Gupta N, et al. Chemoradiotherapy for locally advanced head and neck cancer: 10-year follow-up of the UK Head and Neck (UKHAN1) trial. Lancet Oncol. 2010;11(1):66-74. doi:10.1016/S1470-2045(09)70306-7

44. Baujat B, Mahé C, Pignon J-P, Hill C. A graphical method for exploring heterogeneity in metaanalyses: application to a meta-analysis of 65 trials. Stat Med. 2002;21:2641-2652. doi:10.1002/sim.1221

45. Blanchard P, Bourhis J, Lacas B, et al. Taxane-cisplatin-fluorouracil as induction chemotherapy in locally advanced head and neck cancers: an individual patient data meta-analysis of the meta-analysis of chemotherapy in head and neck cancer group. J Clin Oncol Off J Am Soc Clin Oncol. 2013;31(23):28542860. doi:10.1200/JCO.2012.47.7802

46. Zhong L, Zhang C, Ren G, et al. Randomized Phase III Trial of Induction Chemotherapy With 
458

459

460

461

462

463

464

465

466

467

468

469

470

471

472

473

474

475

476

477

478

479

480

481

482

483

484

485

486

487

488

489

490

491

Docetaxel, Cisplatin, and Fluorouracil Followed by Surgery Versus Up-Front Surgery in Locally Advanced Resectable Oral Squamous Cell Carcinoma. J Clin Oncol. 2013;31(6):744-751.

doi:10.1200/JCO.2012.43.8820

47. Ghi M., Paccagnella A, Ferrari D, et al. Induction TPF followed by concomitant treatment versus concomitant treatment alone in locally advanced Head and Neck Cancer. A phase II-III trial. Ann Oncol 2017 Sep 12892206-2212. doi:10.1093/annonc/mdx299

48. Takácsi-Nagy Z, Hitre E, Remenár É, et al. Docetaxel, cisplatin and 5-fluorouracil induction chemotherapy followed by chemoradiotherapy or chemoradiotherapy alone in stage III-IV unresectable head and neck cancer: Results of a randomized phase II study. Strahlenther Onkol. 2015;191(8):635-641. doi:10.1007/s00066-015-0829-z

49. Montero-Miranda PH, Ganly I. Survivorship--competing mortalities, morbidities, and second malignancies. Otolaryngol Clin North Am. 2013;46(4):681-710. doi:10.1016/j.otc.2013.04.008

50. Park A, Alabaster A, Shen H, Mell L, Katzel J. Are women with head and neck cancer undertreated? J Clin Oncol 201836 Suppl Abstr LBA6002.

51. Özdemir BCO, Csajka C, Dotto G-P, Wagner AD. Sex Differences in Efficacy and Toxicity of Systemic Treatments: An Undervalued Issue in the Era of Precision Oncology. J Clin Oncol 2018262680-2683.:6.

52. Ildstad ST, Tollerud DJ, Bigelow ME, Remensnyder JP. Squamous cell carcinoma of the head and neck at the Massachusetts General Hospital: a comparison of biologic characteristics in men and women. Surgery. 1986;99(1):7-14.

53. Molina MA, Cheung MC, Perez EA, et al. African American and poor patients have a dramatically worse prognosis for head and neck cancer: An examination of 20,915 patients. Cancer. 2008;113:27972806. doi:10.1002/cncr.23889

54. Roberts JC, Li G, Reitzel LR, Wei Q, Sturgis EM. No Evidence of Sex-Related Survival Disparities among Head and Neck Cancer Patients Receiving Similar Multidisciplinary Care: A Matched-Pair Analysis. Clin Cancer Res. 2010;16(20):5019-5027. doi:10.1158/1078-0432.CCR-10-0755

55. Fakhry C, Westra WH, Wang SJ, et al. The prognostic role of sex, race, and human papillomavirus in oropharyngeal and nonoropharyngeal head and neck squamous cell cancer. Cancer. 2017;123(9):15661575. doi:10.1002/cncr.30353

56. Cook MB, McGlynn KA, Devesa SS, Freedman ND, Anderson WF. Sex disparities in cancer mortality and survival. Cancer Epidemiol Biomark Prev Publ Am Assoc Cancer Res Cosponsored Am Soc Prev Oncol. 2011;20(8):1629-1637. doi:10.1158/1055-9965.EPI-11-0246

57. Blanchard P, Baujat B, Holostenco V, et al. Meta-analysis of chemotherapy in head and neck cancer (MACH-NC): a comprehensive analysis by tumour site. Radiother Oncol J Eur Soc Ther Radiol Oncol. 2011;100(1):33-40. doi:10.1016/j.radonc.2011.05.036 
58. FDA Research, Policy, and Workshops on Women in Clinical Trials. https://www.fda.gov/scienceresearch/specialtopics/womenshealthresearch/ucm131731.htm.

59 Racadot S, Mercier M, Dussart S, et al. Randomized clinical trial of post-operative radiotherapy versus concomitant carboplatin and radiotherapy for head and neck cancers with lymph node involvement. Radiother Oncol. 2008;87(2):164-172. doi:10.1016/j.radonc.2007.12.021

60. Argiris A, Karamouzis MV, Johnson JT, et al. Long-Term Results of a Phase III Randomized Trial of Postoperative Radiotherapy With or Without Carboplatin in Patients With High-Risk Head and Neck Cancer. The Laryngoscope. 2008;118(3):444-449. doi:10.1097/MLG.0b013e31815b48f4

\section{Figure legends}

\section{Figure 1: Hazard ratio of death with loco-regional treatment plus chemotherapy versus locoregional} treatment alone.

This analysis was performed using a fixed-effect model. Heterogeneity is discussed in eTable 6 and in the beginning of Discussion section. The broken line and center of the black diamond correspond to overall pooled hazard ratio (HR) and the horizontal tip of the diamond is the $95 \%$ confidence interval $(95 \% \mathrm{Cl})$. The center of the black square corresponds to the HR of trials. The area of the square and the variance of $(\mathrm{O}-\mathrm{E})$ are proportional to the number of deaths in each trial. Trials are ordered chronologically (oldest at the top of figure). $C T$ = Chemotherapy, LRT = Loco-regional treatment; $\mathrm{O}-\mathrm{E}=$ observed minus expected, $\mathrm{I}^{2}$ $=$ Higgins statistic for heterogeneity, No. = Number. In HNCP trial, the arm on induction CT and the one on induction plus maintenance CT were pooled.

Trial group abbreviations:

AHNTG = Australian Head and neck Trial Group, BNH = B. Nanavati Hospital / Mumbai Group (India), EORTC $=$ European Organisation for Research and Treatment of Cancer, GETTEC = Groupe d'Etude des Tumeurs de la Tête Et du Cou (France), GSTTC = Gruppo di Studio sui Tumori della Testa et del Collo (Italy), HNCP = Head and Neck Contract Program (USA), HNU = Head and Neck UFT (Japan), , INT = US INTer group trial, JHCFUS = Japanese HexyCarbanoyl 5-FluoroUracil Study, KKD = Kanto Koshinetsu District (Japan), LOHNG = Ljubljana Oncology Head and Neck Group (Slovenia), RTOG = Radiation Therapy Oncology Group (USA), SWOG = Southwest Oncology Group (USA), TMH = Tata Memorial Hospital (India), UKHAN = United Kingdom Head And Neck (UKCCR head and Neck Collaborative Group, UK), Yale $=$ Yale University (USA). 
Figure 2: Overall survival curves by treatment arm for all trials and for trial subset defined by timing of chemotherapy

The slopes of the broken lines from year 7 to year 8 are based on the overall death rates in the seventh and subsequent years. Absolute differences are given with their $95 \%$ confidence interval. LRT = Locoregional treatment, $\mathrm{CT}=$ Chemotherapy.

a) All trials; b) Adjuvant chemotherapy trials; c) Induction chemotherapy trials; d) Concomitant chemotherapy trials.

\section{Figure 3: Hazard ratio of death with loco-regional treatment plus chemotherapy versus loco-regional} treatment alone by patient's characteristics.

See Figure 1 Legend for more explanations. $p$ _inter: $p$-value of the test of interaction between individual characteristics and treatment effect. p_trend: $p$-value of the test for trend; $P S=$ performance status. $95 \% \mathrm{Cl}=95 \%$ confidence interval $\mathrm{O}-\mathrm{E}=$ observed minus expected, No. = Number.

(a) 4980 patients included in univariate Cox model for interaction.

(b) 4829 patients included in univariate Cox model for interaction.

(c) Missing data in 19 trials (completely missing for BNH003 (124 patients), Cologne (97), Creteil 82 (122), EORTC 24771 (231), EORTC 78-OCP (225), GETTECadj (286), JHCFUS (191), LOHNG97 (114), Pitie-74 (96), TMHR-4 (135), Toulouse (90), Yale80po (78). Only 2811 patients included in univariate Cox model for interaction (GSTTC86po and SWOG8006 had to be excluded because none of their patients had no patients included in the PS=0 category)

(d) Only 2825 patients included in univariate Cox model for interaction because all trials had not included patients in all 4 categories of interest (GETTECneo2, BNH003, Cologne, Creteil-82, EORTC24771, EORTC24844, EORTC78-OCP, GSTTC86po, HNCP, KKD-86, Pitie-74, TMHR-4)

(e) Information on stage was not available for 2 trials (Pitie74 (96) and TMHR-4 (135)).Only 4405 patients included in univariate Cox model for interaction (BNH003, GSTTC86po and LOHNG97 were excluded because of the absence of stage I or II patients);

\section{Figure 4: Overall survival curves by treatment arm for all trials according to sex.}

On the right: men overall survival according to treatment. On the left: female overall survival according to treatment arm. The slopes of the broken lines from year 7 to year 8 are based on the overall death rates in the seventh and subsequent years. Absolute differences are given with $95 \%$ confidence interval. LRT = Loco-regional treatment, CT = Chemotherapy.

\section{Figure 5: Cumulative incidence by treatment arm for each type of event (for overall analysis and for} each timing of chemotherapy). 
561 Given $p$ values correspond to the comparisons of cumulative incidence between treated and non-treated 562 patients (stratified Fine and Gray test). The top left figure represents overall analysis.

$563 \mathrm{CT}=$ Chemotherapy; LRT = Locoregional treatment

564

565 
Figure 1: Hazard ratio of death with loco-regional treatment plus chemotherapy versus loco-regional treatment alone.

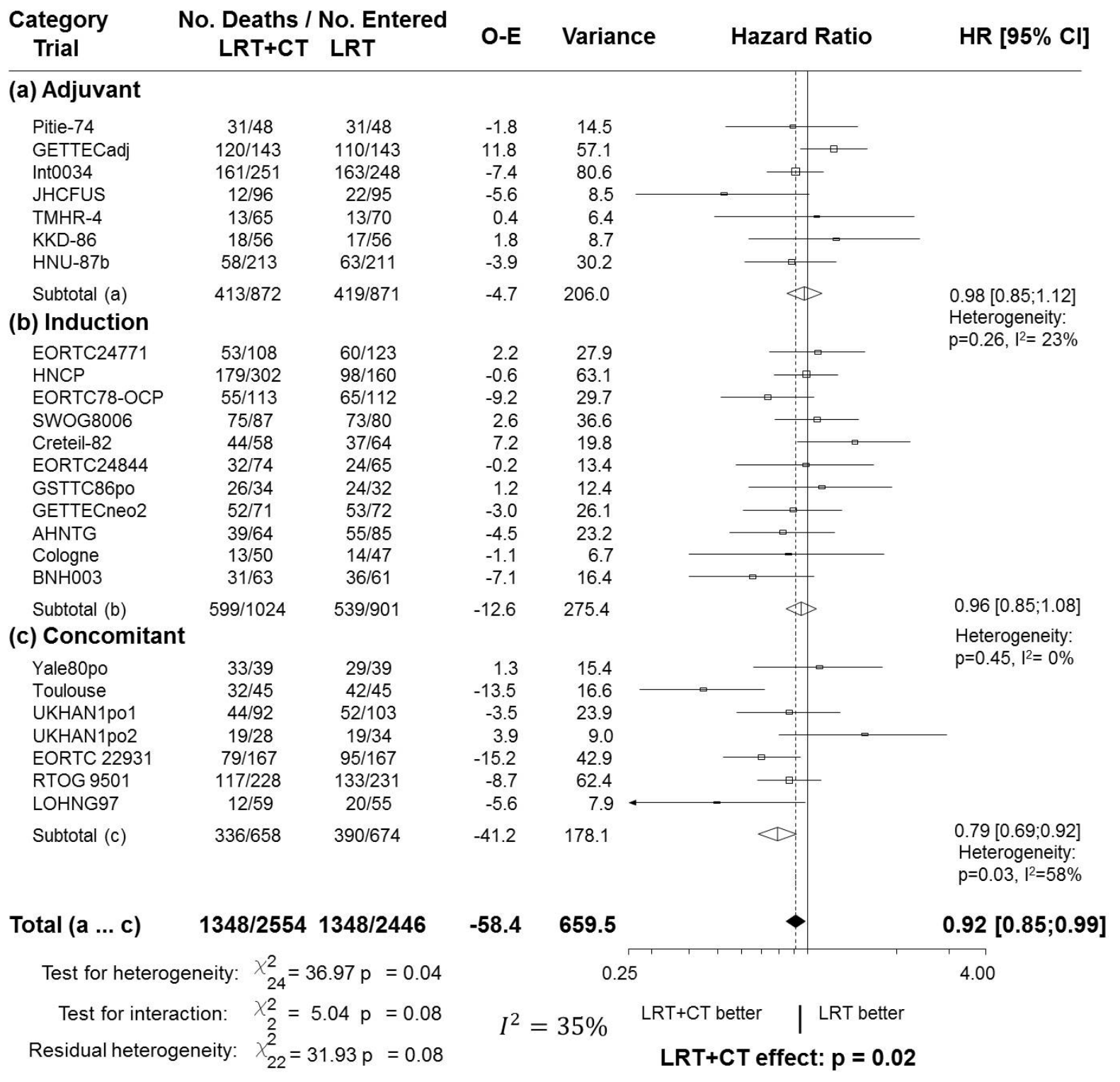


Figure 1: Hazard ratio of death with loco-regional treatment plus chemotherapy versus locoregional treatment alone.

This analysis was performed using a fixed-effect model. Heterogeneity is discussed in eTable 6 and in the beginning of Discussion section. The broken line and center of the black diamond correspond to overall pooled hazard ratio $(\mathrm{HR})$ and the horizontal tip of the diamond is the $95 \%$ confidence interval $(95 \% \mathrm{Cl})$. The center of the black square corresponds to the HR of trials. The area of the square and the variance of (O-E) are proportional to the number of deaths in each trial. Trials are ordered chronologically (oldest at the top of figure). $\mathrm{CT}=$ Chemotherapy, LRT = Loco-regional treatment; $\mathrm{O}-\mathrm{E}=$ observed minus expected, $\mathrm{I}^{2}$ $=$ Higgins statistic for heterogeneity, No. = Number. In HNCP trial, the arm on induction CT and the one on induction plus maintenance CT were pooled.

Trial group abbreviations:

AHNTG = Australian Head and neck Trial Group, BNH = B. Nanavati Hospital / Mumbai Group (India), EORTC = European Organisation for Research and Treatment of Cancer, GETTEC = Groupe d'Etude des Tumeurs de la Tête Et du Cou (France), GSTTC = Gruppo di Studio sui Tumori della Testa et del Collo (Italy), HNCP = Head and Neck Contract Program (USA), HNU = Head and Neck UFT (Japan), , INT = US INTer group trial, JHCFUS = Japanese HexyCarbanoyl 5-FluoroUracil Study, KKD = Kanto Koshinetsu District (Japan), LOHNG = Ljubljana Oncology Head and Neck Group (Slovenia), RTOG = Radiation Therapy Oncology Group (USA), SWOG = Southwest Oncology Group (USA), TMH = Tata Memorial Hospital (India), UKHAN = United Kingdom Head And Neck (UKCCR head and Neck Collaborative Group, UK), Yale $=$ Yale University (USA). 
Figure 2: Overall survival curves by treatment arm for all trials and for trial subset defined by timing of chemotherapy

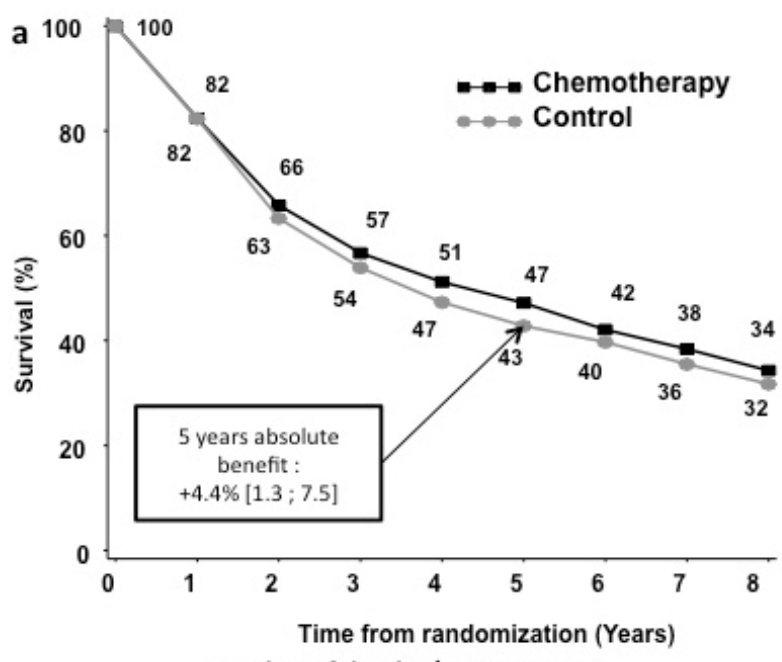

Number of deaths / person-years

[0 to 2] years ]2 to 5] years $] 5$ years +

$\begin{array}{llll}\text { LRT+ CT } & 833 / 4015 & 356 / 3013 & 159 / 1431 \\ \text { LRT Alone } & 851 / 3801 & 370 / 2699 & 127 / 1305\end{array}$

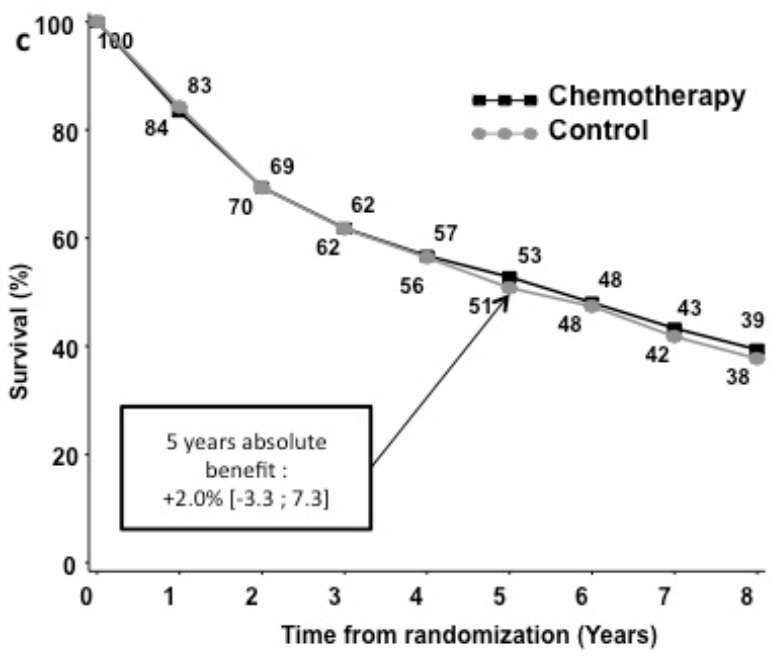

Number of deaths / person-years

$\begin{array}{llll} & {[0 \text { to } 2] \text { years }} & \text { ]2 to 5] years } & \text { ]5 years + } \\ \text { LRT+ CT } & 253 / 1393 & 104 / 1100 & 56 / 564 \\ \text { LRT Alone } & 253 / 1383 & 116 / 1093 & 50 / 527\end{array}$

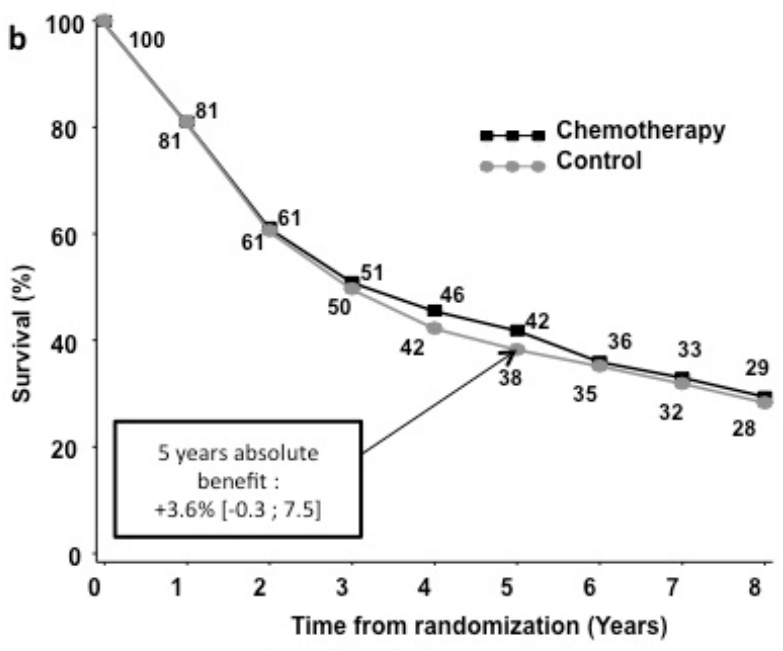

Number of deaths / person-years

[ 0 to 2] years ]2 to 5] years ]5 years +

LRT+ CT $\quad 377 / 1558 \quad 151 / 1122 \quad 71 / 585$

LRT Alone $\quad 328 / 1360 \quad 155 / 938 \quad 56 / 148$

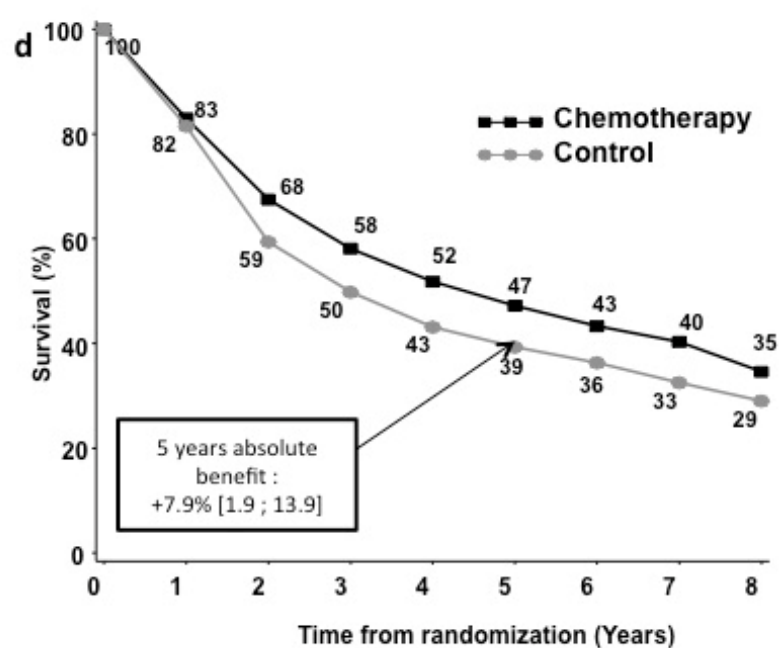
Number of deaths / person-years

[0 to 2] years ]2 to 5] years 15 years +

LRT+ CT $\quad 203 / 1064 \quad 101 / 790 \quad 32 / 281$

$\begin{array}{llll}\text { LRT Alone } & 270 / 1057 & 99 / 667 & 21 / 228\end{array}$ 
Figure 2: Overall survival curves by treatment arm for all trials and for trial subset defined by timing of chemotherapy

The slopes of the broken lines from year 7 to year 8 are based on the overall death rates in the seventh and subsequent years. Absolute differences are given with their $95 \%$ confidence interval. LRT $=$ Locoregional treatment, $\mathrm{CT}=$ Chemotherapy.

a) All trials; b) Adjuvant chemotherapy trials; c) Induction chemotherapy trials; d) Concomitant chemotherapy trials. 
Figure 3: Hazard ratio of death with loco-regional treatment plus chemotherapy versus loco-regional treatment alone by patient's characteristics.

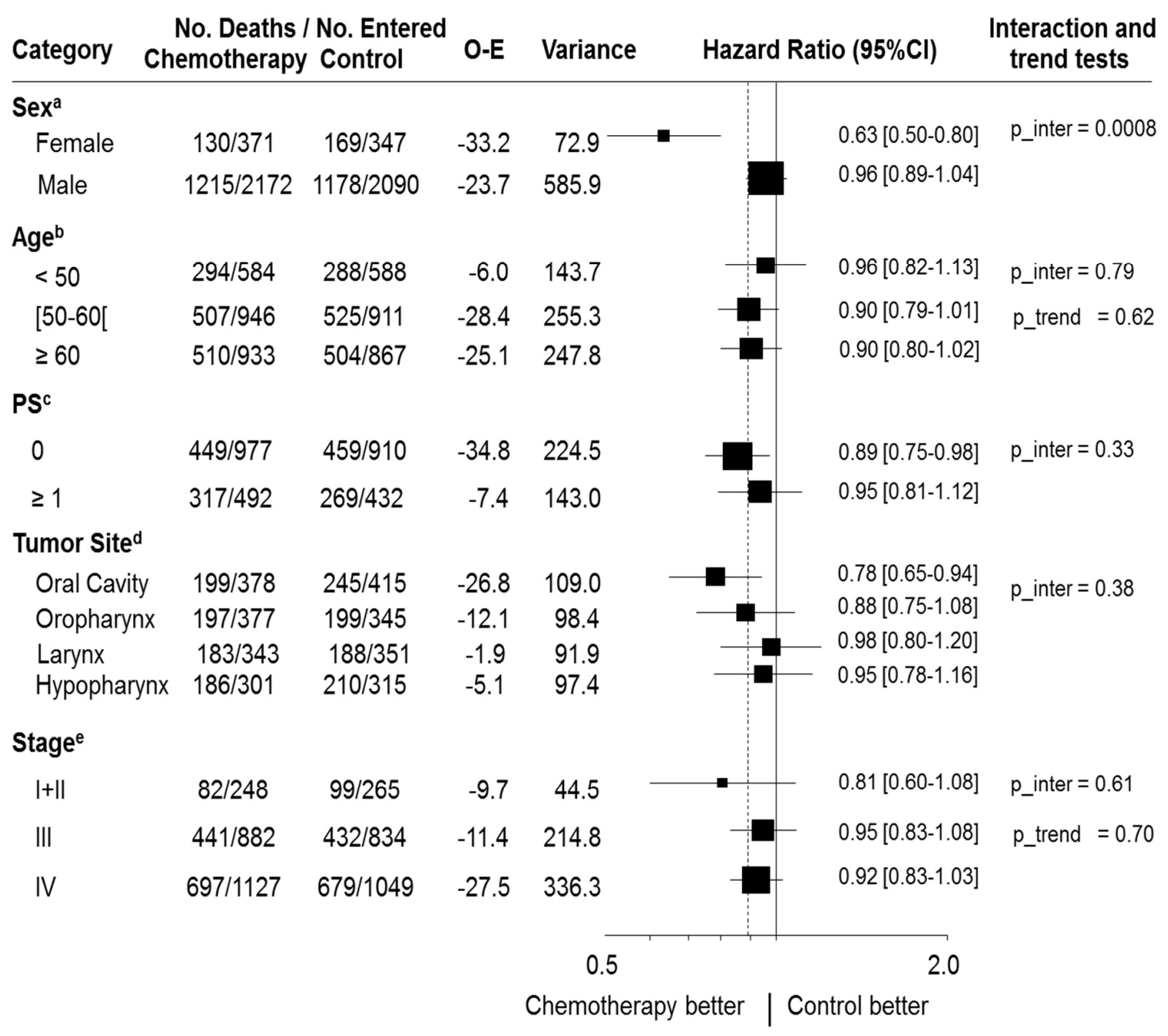


Figure 3: Hazard ratio of death with loco-regional treatment plus chemotherapy versus loco-regional treatment alone by patient's characteristics.

See Figure 1 Legend for more explanations.

p_inter: $p$-value of the test of interaction between individual characteristics and treatment effect.

p_trend: $p$-value of the test for trend; $P S=$ performance status. $95 \% \mathrm{Cl}=95 \%$ confidence interval

$\mathrm{O}-\mathrm{E}=$ observed minus expected, No. = Number.

(a) 4980 patients included in univariate Cox model for interaction.

(b) 4829 patients included in univariate Cox model for interaction.

(c) Missing data in 19 trials (completely missing for BNH003 (124 patients), Cologne (97), Creteil 82 (122), EORTC 24771 (231), EORTC 78-OCP (225), GETTECadj (286), JHCFUS (191), LOHNG97 (114), Pitie-74 (96), TMHR-4 (135), Toulouse (90), Yale80po (78). Only 2811 patients included in univariate Cox model for interaction (GSTTC86po and SWOG8006 had to be excluded because none of their patients had no patients included in the PS=0 category)

(d) Only 2825 patients included in univariate Cox model for interaction because all trials had not included patients in all 4 categories of interest (GETTECneo2, BNH003, Cologne, Creteil-82, EORTC24771, EORTC24844, EORTC78-OCP, GSTTC86po, HNCP, KKD-86, Pitie-74, TMHR-4 )

(e) Information on stage was not available for 2 trials (Pitie74 (96) and TMHR-4 (135)).Only 4405 patients included in univariate Cox model for interaction (BNH003, GSTTC86po and LOHNG97 were excluded because of the absence of stage I or II patients); 
Figure 4: Overall survival curves by treatment arm for all trials according to sex.

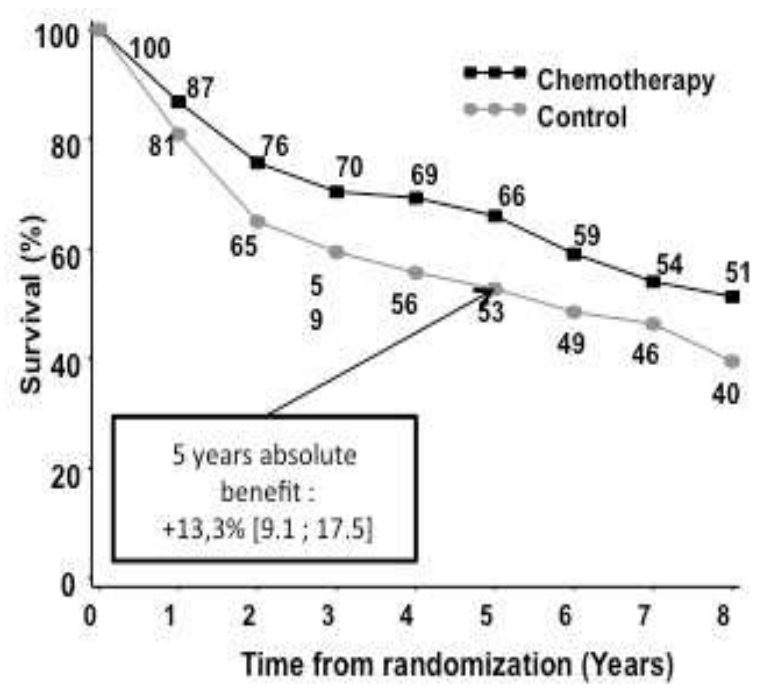

Number of deaths / person-years

[0 to 2] years $] 2$ to 5 ] years $] 5$ years +

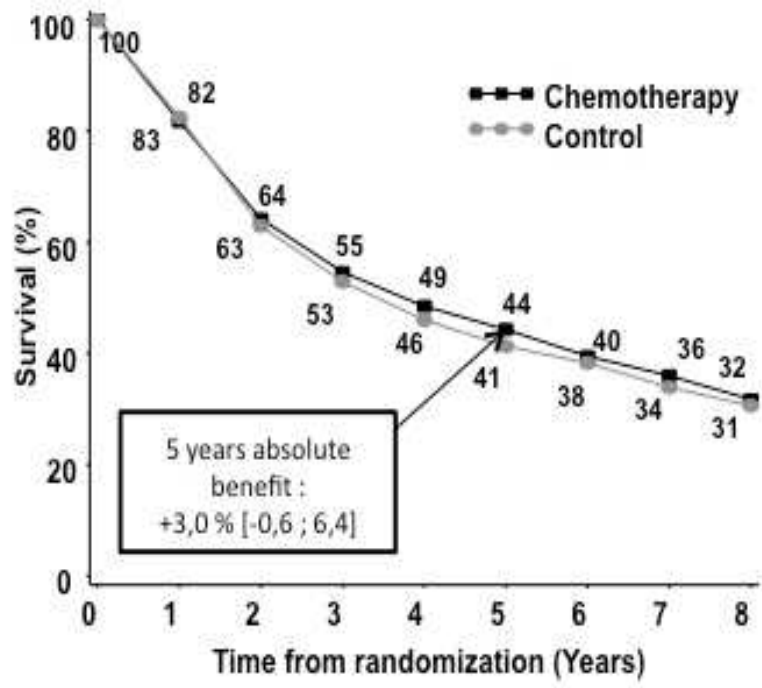

Number of deaths / person-years

[0 to 2] years ]2 to 5] years $] 5$ years +

$\begin{array}{llll}\text { LRT+CT } & 748 / 3405 & 330 / 2494 & 137 / 1170\end{array}$

LRT Alone $735 / 3270 \quad 338 / 2286 \quad 105 / 1104$

Figure 4: Overall survival curves by treatment arm for all trials according to sex.

On the right: men overall survival according to treatment. On the left: female overall survival according to treatment arm. The slopes of the broken lines from year 7 to year 8 are based on the overall death rates in the seventh and subsequent years. Absolute differences are given with $95 \%$ confidence interval. $\mathrm{LRT}=$ Loco-regional treatment, $\mathrm{CT}=$ Chemotherapy. 
Figure 5: Cumulative incidence by treatment arm for each type of event (for overall analysis and for each timing of chemotherapy).
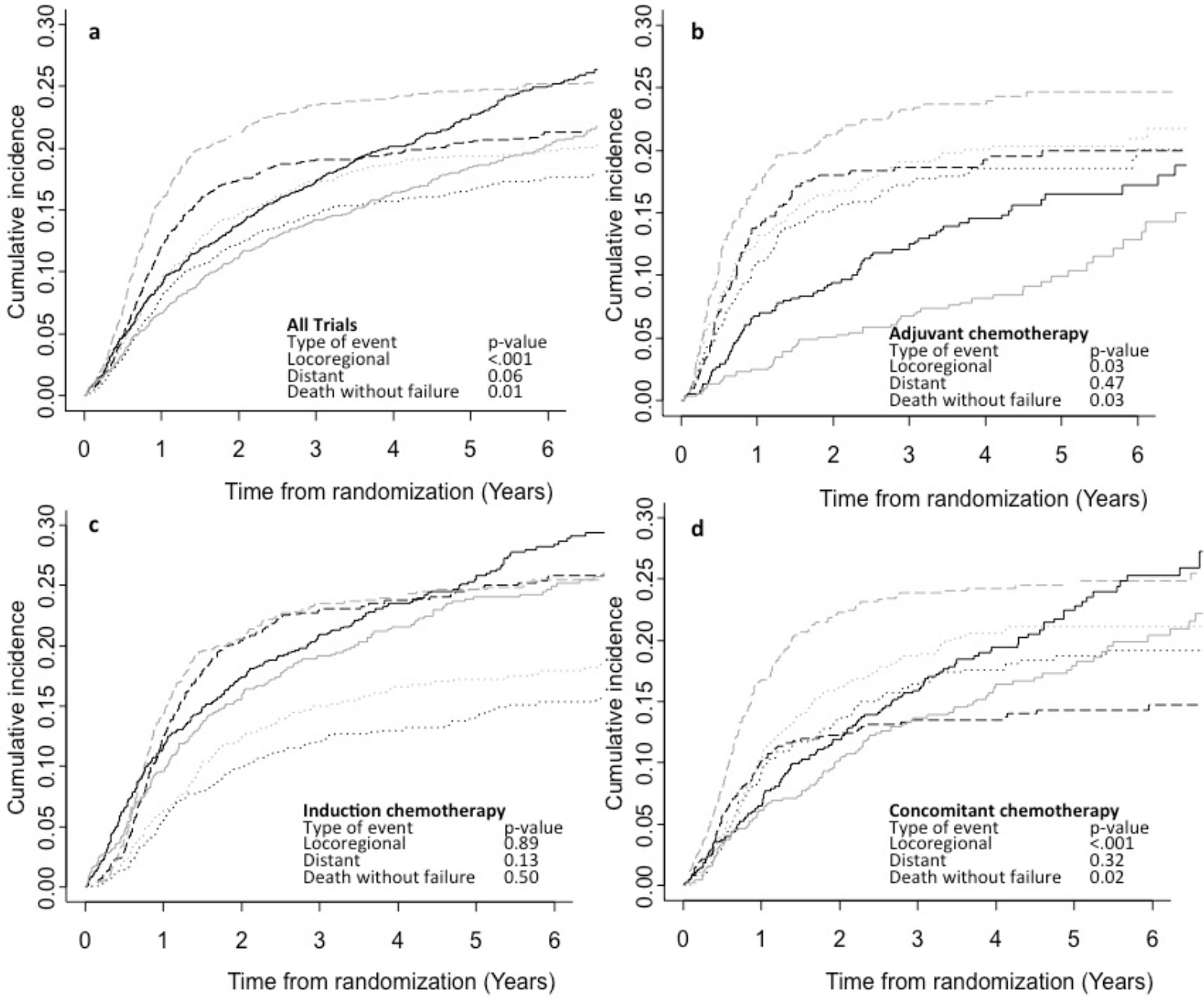

--. Local failure (CT) Local failure (LRT)

Distant failure (CT)

Distant failure (LRT)

Dead with no failure (CT)

Dead with no failure (LRT)

Figure 5: Cumulative incidence by treatment arm for each type of event (for overall analysis and for each timing of chemotherapy).

Given p-values correspond to the comparisons of cumulative incidence between treated and non-treated patients (stratified Fine and Gray test). a) All trials; b) Adjuvant chemotherapy trials; c) Induction chemotherapy trials; d) Concomitant chemotherapy trials. CT = Chemotherapy; LRT = Locoregional treatment 